\title{
An All-Organic Porphyrin and its Properties
}

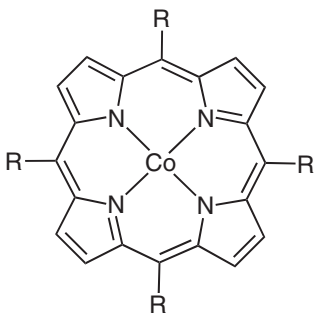

1) $\mathrm{ICCl}, \mathrm{FeCl}_{3}$ $\mathrm{CH}_{2} \mathrm{Cl}_{2}, 22^{\circ} \mathrm{C}, 1 \mathrm{~h}$

2) $\mathrm{aq} \mathrm{K}_{2} \mathrm{CO}_{3}$

$\mathrm{CH}_{2} \mathrm{Cl}_{2}$

$82 \%$ yield

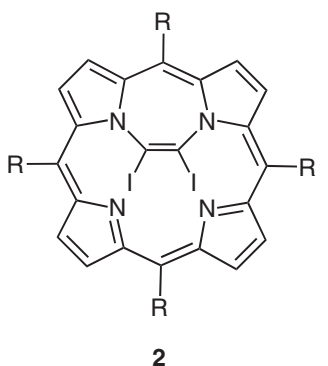

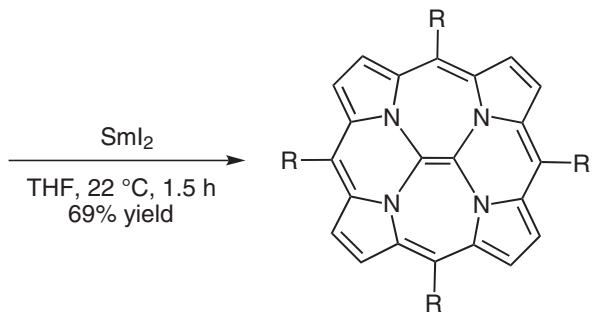

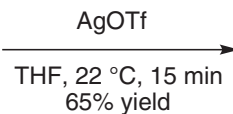

$65 \%$ yield

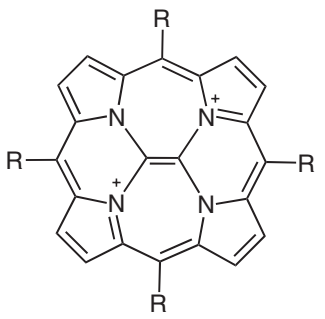

$\mathrm{R}=p-\mathrm{Tol}$

Significance: Reaction of cobalt porphyrin $\mathbf{1}$ with diiodoacetylene in the presence of $\mathrm{FeCl}_{3}$ followed by treatment with $\mathrm{K}_{2} \mathrm{CO}_{3}$ affords compound $\mathbf{2}$, which is reduced with $\mathrm{Sml}_{2}$ to form porphyrin 3 . Characterization of this neutral $\mathrm{C}=\mathrm{C}$ porphyrin reveals alternating single and double $\mathrm{C}-\mathrm{C}$ bonds, owing to the antiaromatic properties of the compound. Further, cyclic voltammetry measurements indicate an easy oxidation of $\mathbf{3}$ to its dicationic, $18 \pi$-electron aromatic form. Chemical oxidation of $\mathbf{3}$ in the presence of AgOTf affords ionic species 4. NMR measurements and DFT calculations confirm the aromatic character of $\mathbf{4}$, that does not possess alternating single and double $\mathrm{C}-\mathrm{C}$ bonds.
Comment: Although the typical aromatic character of porphyrins is preserved in compound $\mathbf{4}$, its electronic structure significantly differs from that of classical metalloporphyrins. In particular, the UV/Vis absorbance spectrum of $\mathbf{4}$ features several intense bands where the single Soret band is usually observed for porphyrins. Such properties make this new type of porphyrins of potential interest for light-harvesting systems.

\section{Key words}

porphyrins

macrocycles

aromaticity

SYNFACTuth 